\title{
NUMERICAL SIMULATION OF RING ROLLING PROCESS FOR Ni-BASE ARTICLES
}

\author{
T.Matsui ${ }^{1}$, H.Takizawa ${ }^{2}$ and H.Kikuchi ${ }^{3}$ \\ Mitsubishi Materials Co. Ltd, Saitama, Japan \\ ${ }^{1} 476$ Shimoishido-Shimo, Kitamoto, Saitama, 364-0023, Japan \\ ${ }^{2}$ 1-297 Kitabukuro-cho, Omiya, Saitama, Saitama, 330-8508, Japan \\ ${ }^{3} 1230$ Kamihideya, Okegawa, Saitama, 363-8510, Japan
}

keywords: ring rolling, computer simulation, microstructure prediction, casing, seal

\begin{abstract}
Continuous improvements of properties for individual parts are indispensable for perpetual development of aircraft engines. Concerning casing and seal, simulation of ring rolling process is one of the most attractive tools to reduce the cost and time and to improve the properties and the reliability at the same time. In order to obtain both practical prediction accuracy and acceptable computation time from industrial standpoint, the refined partial three-dimensional deformation model was proposed. Moreover the relationship between microstructure evolution and various parameters regarding to Waspaloy* was evaluated and microstructure prediction models were developed. Constructed microstructure prediction models were coupled to the finite element analyzing system to estimate mean grain diameter and fraction of recrystallization in addition to general output e.g. temperature, strain. The effectiveness of proposed prediction system as a process design tool was confirmed through multi compression test and production of actual casing that had extremely complicated near-net-shape.
\end{abstract}

\section{Introduction}

Improvement of hot section parts has been contributed to development of aircraft engine and is indispensable for further development. In particular it is important to meet following three tasks.

1) Reduction of lead-time and cost in developmental stage

2) Suppression of production cost

3) Optimization of materials properties

The reduction of lead-time to develop new engines or to modify existing ones tends to be accelerated in order to suppress the development cost. This tendency requires shorter lead-time of individual parts development or improvement. It means that designated shape and properties of each part have to be achieved in extremely limited time. It becomes difficult to cope with such trend by usual trial and error procedure.

Suppression of production cost is uninterrupted matter up to now and in future. One of effective ways to reduce the production cost is hastening of near-net-shape technology that makes it possible to improve fly-to-buy ratios and to suppress machining cost However this technology brings drastic difficulty in shape, dimension and quality control. Therefore it is not easy to find desirable process condition and to produce suitable parts all the time.

Development of aircraft engine also requires the improvement of

*Waspaloy is a trademark of United Technologies Corporation. mechanical properties in individual critical parts. To meet such requirements, several kinds of new materials that have more desirable mechanical properties were proposed and evaluated. However most of these materials have some disadvantages e.g. cost, reliability. Therefore actual application of these new materials was limited. Another effective way to improve the performance of parts is optimization of existing materials. Optimization means to maximize the potential of existing materials and to suppress scatter of product quality in order to achieve practical improvement of design curves. However, in actual articles that have complicated shapes, it is difficult to optimize the microstructure and mechanical properties in whole region within restricted development schedule. The tendency to shorten development lead-time makes it more difficult.

Numerical simulation technology is one of the most attractive tools to solve these problems and the effectiveness of this technology was confirmed in various applications. Typical successful case is in production of turbine and compressor disks that are the most important major rotating parts in aircraft engines. Some kinds of advanced numerical simulation system related to disk forging are able to predict directly microstructure and mechanical properties in addition to deformation during forging process[1-5]. Consequently such numerical simulations bring not only improvement of practical mechanical properties but also higher reliability and reduction of huge amount of trial and production cost.

Recently, similar needs tend to extend to other parts represented by casing and seal. In general, many articles regarding to ring rolling process were made, and the change of shape and microstructure during the process were complicated compared to those in disk forging. Schematic drawing of ring rolling process is shown in Figure 1. In this process, doughnut-shaped work piece is formed mainly using two kinds of roll: driving and pressure roll. Driving roll contacts the outer surface of seamless ring and rotates the work piece by frictional force. Pressure roll positioned inside of the work piece moves toward the driving roll together with free rotation. It is one of characteristic features in this process that all of rolls and work piece change each position continuously during the process. Such free movement and revolution makes it difficult to handle ring-rolling process on computer simulation system. Besides above difficulty, large number of local contacts between work piece and each roll is repeated and this intermittent forming causes drastic and local change of temperature and strain rate in roll-bite region. Application of near-net-shape technology makes the deformation behavior even more complicated. Therefore it is difficult to understand deformation behavior and to predict the microstructure evolution during ring rolling process. The fact indicates that optimization of shape and microstructure in ring rolling process is by no means easy and numerical simulation 


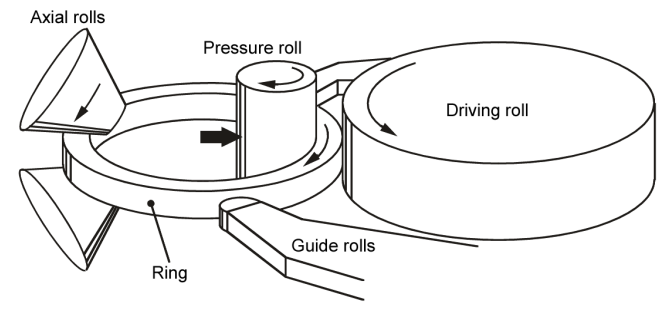

Figure 1. Schematic drawing of ring rolling process

technology is worth developing.

On the other hand, from the viewpoint of material, typical high strength $\mathrm{Ni}$ base superalloy, Waspaloy is one of the most important materials for casing and seal, because this alloy has both attractive mechanical properties at service temperature and practical formability in production stage. Therefore prediction system for casing and seal made with Waspaloy is of great value. Quite a number of reports that describe the effect of process condition on microstructure evolution in Waspaloy had been published in the past[2,6,7]. While these are available for understanding of particular behavior in individual processing stage, it is difficult to represent characteristic of total changes in microstructure during ring rolling process systematically by means of published data. The objectives of this investigation are to propose ring rolling simulation system that has both adequate prediction accuracy and acceptable calculation time for industrial use and to establish the prediction procedure that enable us to understand not only deformation behavior but also microstructure evolution in Waspaloy casing and seal production.

\section{Partial Three-dimensional Deformation Model}

Some kinds of ring rolling simulation techniques using finite element method were reported up to now. However many of previous simulation techniques are not suitable for actual process design because of following reasons. In full three-dimensional model, it requires considerable amount of calculation time whereas precise prediction is expected[8-10]. While extended two-dimensional model with generalized plane strain or axisymmetric approximation realizes acceptable calculation time, it doesn't have adequate accuracy for practical use because of oversimplified modeling of complicated phenomena[11,12]. Partial three-dimensional model has intermediate feature of above two methods and has the possibility for practical application[13,14]. However previous partial three-dimensional model couldn't trace actual deformation precisely because of some assumptions on deformation to simplify the model. In this model, velocity boundary conditions on imaginary cutting planes are given as rigid rotation around the fixed center of ring. Therefore such model can't consider the enlargement of the diameter despite of drastic change in diameter during ring rolling process. Moreover, this model assumed iteration of steady-state

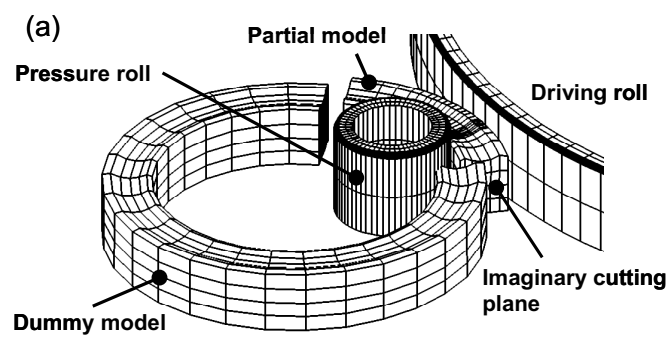

(b)

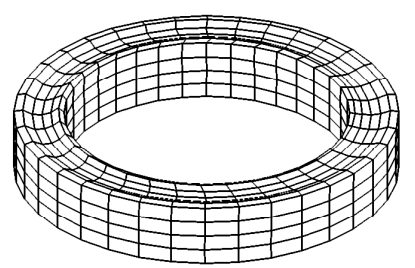

Figure 2. Schematic drawing of developed three-dimensional model (a) for deformation analysis (b) for microstructure analysis.

deformation in spite of non-steady one in actual production. As the results, there are few effective simulation techniques for industrial application and the utilization is limited for basic understanding of deformation during rolling process focused on specific region.

In order to achieve both practical prediction accuracy and acceptable computation time from industrial standpoint, the partial three-dimensional finite element model is refined by novel velocity boundary conditions on imaginary cutting planes. Figure 2(a) shows schematic drawing of proposed three-dimensional model. The details of basic idea and its effectiveness of developed model had already been published[15,16]. This model enables us to deal with deformation as transient matter and allows movement of rotational center, change of diameter in ring just like actual production by assuming following conditions.

1) Elongation of circumferential length occurs only in modeled portion.

2) Non-modeled portion keeps an arc of circle.

3 ) The center of the ring lies on the straight line connected by the center of driving roll and that of pressure roll.

All assumptions trace practical phenomena approximately. Axial rolls don't give large deformation induced enlargement of diameter. Rings keep circular shape during rolling process in spite of continuous enlargement of diameter. The center of ring is kept on the centerline of the rolling mill by guide rolls. These features bring adequate accuracy equivalent to full three-dimensional model despite of relatively short calculation time. Remaining portion that is not considered as partial model is defined as dummy model to interpolate state variables such as equivalent plastic strain. Moreover the spatial fixed (Eulerian) mesh is

Table I. Calculation conditions of plain ring rolling process

\begin{tabular}{ccccc}
\hline Radius of driving roll & \multicolumn{2}{c}{ Radius of pressure roll } & Angular velocity of driving roll & Feed speed of pressure roll \\
\hline $595.0 \mathrm{~mm}$ & \multicolumn{2}{c}{$62.5 \mathrm{~mm}$} & $2.79 \mathrm{rad} \cdot \mathrm{s}-1$ & $4.0 \mathrm{~mm} \cdot \mathrm{s}-1$ \\
\hline \multicolumn{2}{c}{ Initial dimensions of work piece } & \multirow{2}{*}{$\begin{array}{l}\text { Thickness } \\
\text { reduction }\end{array}$} \\
\hline Height & Inner radius & Outer radius & & Remarks \\
\hline $63.5 \mathrm{~mm}$ & $70.5 \mathrm{~mm}$ & $158.4 \mathrm{~mm}$ & $14 \%$ & $\begin{array}{c}\text { Constant flow stress } \\
\text { (rigid-perfectly plastic material) }\end{array}$ \\
\hline
\end{tabular}


(a)
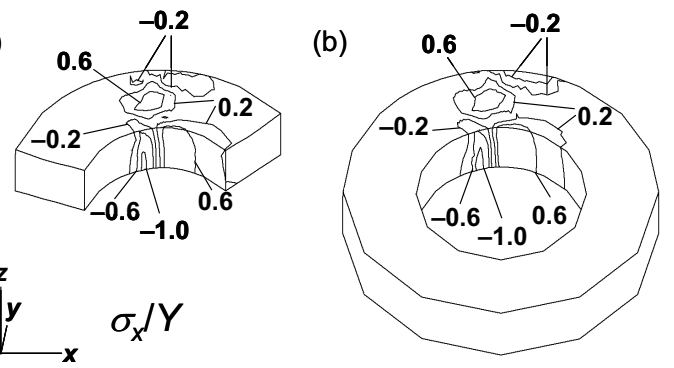

Figure 3. Calculated stress $\sigma_{\mathrm{x}}$ distribution on plain ring rolling process (a) proposed partial three-dimensional model (b) conventional full three-dimensional one.

utilized in rotational direction to keep fine mesh condition in rollbite region. Thermal analysis is carried out in both partial and dummy portion to simulate temperature change during entire rolling process. Figure 3 shows comparison of stress $\sigma_{\mathrm{x}}$ distribution on plain ring rolling process calculated by proposed partial three-dimensional model and full three-dimensional model. Calculation conditions are described in Table I. Proposed partial three-dimensional model brings equivalent results to that of full three-dimensional model in any region although proposed model requires extremely shorter calculation time than that of full threedimensional model, less than one tenth in this case.

\section{Microstructure Model}

Microstructure of ring rolling article is influenced by various parameters e.g. time, temperature, strain rate and strain. To reveal the essential relationship between microstructure and such variables, several kinds of metallurgical test including isothermal heating test, strain rate controlled isothermal compression test were performed and numerical data were gained. Two kinds of microstructure prediction model concerned to Waspaloy were developed through above quantitative analysis. One was static grain growth model that mainly corresponded to preheating process prior to ring rolling and the other was recrystallization model that represented ring rolling process itself. Moreover, constructed microstructure prediction models were coupled to the finite element analyzing system and enable us to estimate mean grain diameter and fraction of recrystallization in addition to general output such as, temperature, strain on the whole area of ring rolled products.

\section{$\underline{\text { Static Grain Growth Model }}$}

Isothermal heating test was conducted to understand the static grain growth behavior. All of tested materials in this study including the following various evaluations were the forgings and rings produced from double melted ingot (VIM+ESR). Chemical composition of tested material is shown in Table II. The specimens which had several kinds of initial grain diameter were put into furnace in which was controlled at specific temperature and were kept for set time. The range of temperature is 1010$1100^{\circ} \mathrm{C}$. Microstructure observation was performed by optical microscopy and grain diameter was estimated in accordance with ASTM E112.

The relationship between grain diameter and holding time is shown in Figure 4(a). The higher the temperature is, the larger the grain growth rate is. The tendency is obvious above gamma prime solvus temperature. Furthermore Figure 4(a) reveals that the relationship can be represented by following equation and the exponent $\mathrm{n}$ takes 3 in this case:

$$
\mathrm{d}_{\mathrm{i}+1}{ }^{\text {ngro }}-\mathrm{d}_{\mathrm{i}}{ }^{\mathrm{ngro}}=\mathrm{A}_{\mathrm{gro}}\left(\mathrm{t}_{\mathrm{i}+1}-\mathrm{t}_{\mathrm{i}}\right) \exp \left(-\mathrm{Q}_{\mathrm{gro}} / \mathrm{RT}\right)
$$

where $d_{i+1}$ is the grain diameter when time is $t_{i+1}, d_{i}$ is the grain diameter when time is $t_{i}, t$ is time, $Q_{\text {gro }}$ is the activation energy for grain growth, $\mathrm{T}$ is in absolute temperature, $\mathrm{R}$ is the gas constant and $\mathrm{A}_{\text {gro }}, \mathrm{n}_{\text {gro }}$ are material constants. Generally the exponent $\mathrm{n}_{\text {gro }}$ varies from 2 to 4 with rate-controlling process of grain growth. In case of dispersion structure in which dispersion particle plays as pinning of grain boundary, volume diffusion of atom which constructs dispersion particle controls not only growth of particle but also that of grain and $\mathrm{n}_{\text {gro }}$ takes a value of 3 . It does not need to say that the equation (1) represents essentially steady state grain growth with no internal strain. Therefore $\mathrm{n}_{\text {gro }}$ might be affected by the stored strain and dispersion condition of particles caused by prior process. However the estimated exponent, 3, is supposed to be valid for not only Waspaloy but also similar other Ni-base superalloys with dispersed carbide, nitride and boride[1]. Moreover the effect of previous process history is found in the value of apparent activation energy $Q_{\text {gro }}$ and the value is larger than that of volume diffusion of Ni or alloying element in $\mathrm{Ni}$.

\section{Recrystallization Model}

Strain rate controlled isothermal compression tests were carried out to understand the essential relationship between temperature, strain rate, strain and microstructure evolution i.e. dynamically recrystallized grain diameter, fraction of dynamic recrystallization, grain growth right after deformation. Chemical composition of tested material is shown in Table II. The specimens obtained from forged billet were cylindrical shape with $8 \mathrm{~mm}$ in diameter and $12 \mathrm{~mm}$ in height. These specimens were heated up to test temperature by induction heating and compressed. Each range of temperature, strain rate and total strain is $900-1150^{\circ} \mathrm{C}, 0.01-0.2 \mathrm{~s}^{-1}$ and $5-70 \%$ respectively. The specimens were cooled immediately or after keeping test temperature for definite time to achieve quench or dwelt condition. Microstructure observation was carried out by optical microscopy for specific area with $1 / 2$ in height and $2 / 3$ in radius. The area was selected by finite element analysis as desirable observation points in which uniform conditions e.g. strain rate, temperature were achieved through compression. The results of microstructure observation were associated to test temperature, revised strain rate and total strain.

Table II. Chemical composition of evaluated materials

\begin{tabular}{ccccccccccc}
\hline & $\mathrm{Ni}$ & $\mathrm{Cr}$ & $\mathrm{Co}$ & $\mathrm{Mo}$ & $\mathrm{Al}$ & $\mathrm{Ti}$ & $\mathrm{Zr}$ & $\mathrm{B}$ & $\mathrm{C}$ & Remarks \\
\hline \multirow{6}{*}{ Waspaloy } & bal. & 19.0 & 13.9 & 4.3 & 1.4 & 2.9 & 0.05 & 0.005 & 0.03 & Isothermal heating test \\
& bal. & 19.4 & 12.9 & 4.3 & 1.4 & 2.8 & 0.04 & 0.006 & 0.03 & Single and multi compression test \\
& bal. & 18.9 & 13.3 & 4.2 & 1.5 & 2.8 & 0.06 & 0.006 & 0.03 & Actual casing \\
\hline
\end{tabular}


One of the most important metallurgical phenomena to understand is the occurrence of dynamic recrystallization. Dynamic recrystallization enables to bring desirable microstructure that consists of uniform, equiaxed grains. Figure 4(b) shows the relationship between dynamically recrystallized grain diameter and Zener-Hollomon parameter that represented with the following equation:

$$
\mathrm{d}_{\mathrm{dyn}}=\mathrm{A}_{\mathrm{dyn}} \mathrm{Z}^{\mathrm{ndyn}}
$$

where $d_{d y n}$ is the dynamically recrystallized grain diameter, $\mathrm{Z}$ is the Zener-Hollomon parameter, $A_{d y n}$ and $n_{d y n}$ are material constants. Zener-Hollomon parameter means temperaturecompensated strain rate and follows as:

$$
\mathrm{Z}=\dot{\varepsilon} \exp \left(\mathrm{Q}_{\mathrm{def}} / \mathrm{RT}\right)
$$

where $\dot{\varepsilon}$ is the strain rate, $Q_{\text {def }}$ is the activation energy for deformation, $\mathrm{T}$ is in absolute temperature, $\mathrm{R}$ is the gas constant Activation energy for deformation $Q_{\text {def }}$ is estimated by following equation that represents deformation behavior at high temperature:

$$
\dot{\varepsilon}=\sigma^{\text {ndef }} \exp \left(-\mathrm{Q}_{\text {def }} / \mathrm{RT}\right)
$$

where $\sigma^{\text {ndef }}$ is the peak stress or steady stress, $n_{\text {def }}$ is a material constant. In this study, peak stress is adopted to estimate $n_{\text {def }}$ and $\mathrm{Q}_{\text {def }}$ in equation (4). The exponent $\mathrm{n}_{\text {def }}$ takes a constant value of 4.3. Corresponding apparent activation energy $\mathrm{Q}_{\text {def }}$ included the effect of non-thermally activated process is $365 \mathrm{kJmol}^{-1}$. Generally, larger value is obtained compared to volume diffusion of $\mathrm{Ni}$ or alloying element in $\mathrm{Ni}$ and similar tendency is observed in this study as mentioned in previous report concerned to another Nibase superalloy[1].

Precise prediction is also required for the fraction of dynamic recrystallization. An Avrami type equation (5) was maintained in this study:

$$
\mathrm{X}_{\mathrm{dyn}}=1-\exp \left\{-\ln 2\left(\varepsilon / \varepsilon_{0.5}\right)^{\mathrm{ndynx}}\right\}
$$

where $\mathrm{X}_{\mathrm{dyn}}$ is the fraction of dynamic recrystallization, $\varepsilon$ is strain, $\varepsilon_{0.5}$ is strain for $50 \%$ dynamic recrystallization, $\mathrm{n}_{\mathrm{dynx}}$ is a constant. $\varepsilon_{0.5}$ is function of Zener-Hollomon parameter and initial grain diameter. This equation shows that fraction of dynamic recrystallization is affected by temperature, strain rate, strain and initial grain diameter. Obtained fitting curve is able to trace the actual tendency quantitatively. The higher the temperature is and the smaller the strain rate is, the higher the fraction of dynamic recrystallization is. In case of ring rolling simulation, precise prediction in lower strain region is important compared to that in forging simulation because only small strain is added by single rolling bite and such forming is repeated.

The remarkable grain growth occurs in actual parts due to the deformation heat and stored strain. It is important to control such phenomena to gain desirable equiaxed and homogeneous grain structure because it is difficult to obtain large fraction of recrystallization only by dynamic recrystallization control. Hence the degree of grain growth right after rolling has to be predicted quantitatively in particular. Figure 4(c) shows the grain growth

(a)

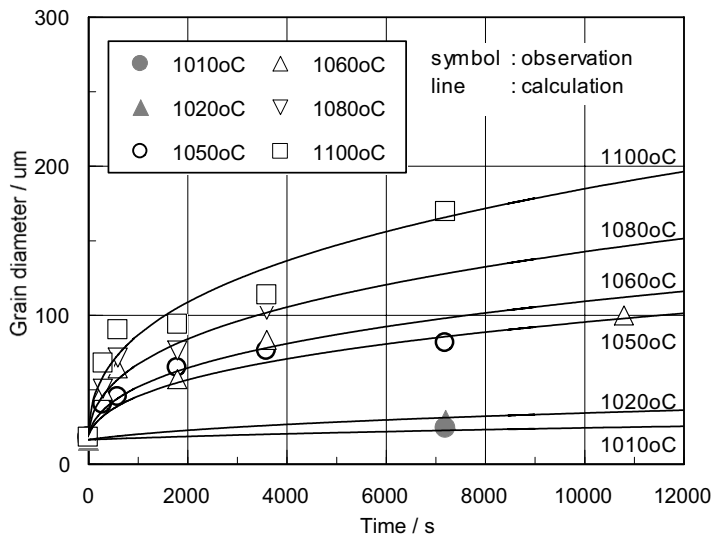

(b)

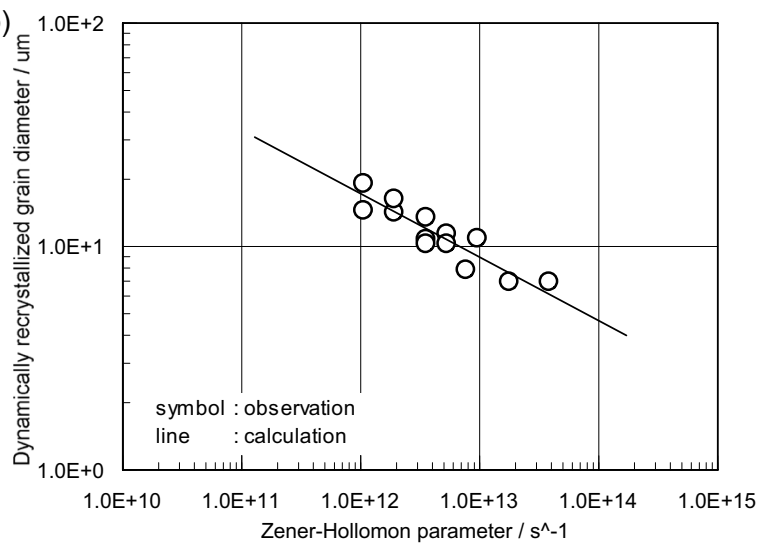

(c)

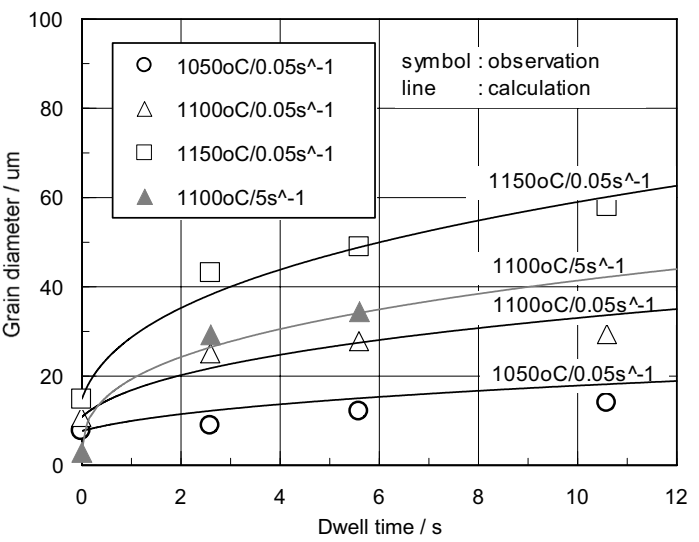

Figure 4. The relationship between grain diameter and various parameters in Waspaloy (a) static grain growth behavior (b) dynamically recrystallized grain diameter as a function of ZenerHollomon parameter (c) grain growth behavior of dynamically recrystallized grain. 
behavior of dynamically recrystallized grain after isothermal compression. Very rapid grain growth tendency is observed. The relationship between grain diameter and dwell time is described with following equation (6) similar to equation (1):

$$
\mathrm{d}_{\text {dwe }}{ }^{\text {ndgr }}-\mathrm{d}_{\text {com }}{ }^{\text {ndgr }}=\mathrm{A}_{\text {dgr }} \mathrm{t} \exp \left(-\mathrm{Q}_{\mathrm{dgr}} / \mathrm{RT}\right)
$$

where $d_{d w e}$ is the grain diameter after dwell, $d_{\text {com }}$ is the grain diameter just after compression, $A_{d g r}$ is a function of strain rate, $t$ is the dwell time, $\mathrm{Q}_{\mathrm{dgr}}$ is the activation energy for grain growth in dwell condition, $\mathrm{T}$ is the absolute temperature, $\mathrm{R}$ is the gas constant and $\mathrm{n}_{\mathrm{dgr}}$ is a material constant. The exponent $\mathrm{n}_{\mathrm{dgr}}$ takes a value of 3 , which is an identical value in equation (1).

\section{Modeling}

In order to incorporate the microstructure model into thermomechanical analysis, given relationship was formulated as incremental form. Moreover constructed prediction model is able to deal with continuous dynamic recrystallization and grain growth not only in unrecrystallized region but also in recrystallized region like actual metallurgical transformation. Proposed concept concerned to microstructure evolution is shown in Figure 5. Such incremental procedure is indispensable for precise prediction of microstructure. These microstructure evolution models for Waspaloy were coupled with developed three-dimensional thermo-mechanical simulation system. It is necessary to track the thermo-mechanical history of a material point to obtain an accurate microstructure simulation. Therefore the material fixed (Lagrangian) mesh is adopted for microstructure model (Figure 2(b)). The state variables of the material fixed mesh are interpolated appropriately from those of thermo-mechanical mesh mentioned above.

\section{Multi Compression Analysis}

Several kinds of multi compression test which had similar thermal

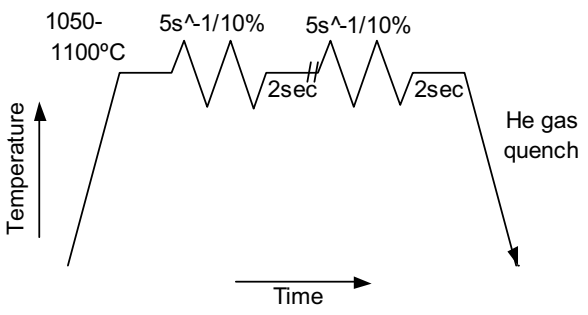

Figure 6. Schematic drawing of forming schedule in multi compression test.

and deformation schedule compared to the ring rolling process were conducted to verify proposed microstructure models. Experimental procedure was much the same as that of single compression mentioned above. Schematic drawing of forming schedule is shown in Figure 6. Heated specimens up to test temperature $1050-1100^{\circ} \mathrm{C}$ were compressed with strain rate of $5 \mathrm{~s}^{-1}$ until $10 \%$ of reduction followed by $2 \mathrm{sec}$ isothermal holding without strain. Such forming was repeated twice or four times not only under isothermal condition but also with temperature transition. Individual deformation and isothermal holding correspond to working in roll-bite region and rotation out of roll gap in ring rolling respectively.

Typical microstructures after multi compression test are shown in Figure 7. Furthermore Figure 8 shows the comparison of mean grain diameter and fraction of recystallization between prediction and observation. Calculation indicates characteristic transitions of mean grain diameter and fraction of recrystallization. Mean grain diameter decreases drastically by occurrence of dynamic recrystallization during deformation and increases by grain growth at intervals of deformation. On the other side, increase of recrystallization ratio by dynamic recrystallization is relatively slight and most of the improvement is obtained by post-dynamic grain growth after deformation. Moreover adequate agreement between calculation and measurement is obtained in both mean grain diameter and fraction of recrystallization despite their complicated forming history, i.e. reiteration of deformation,

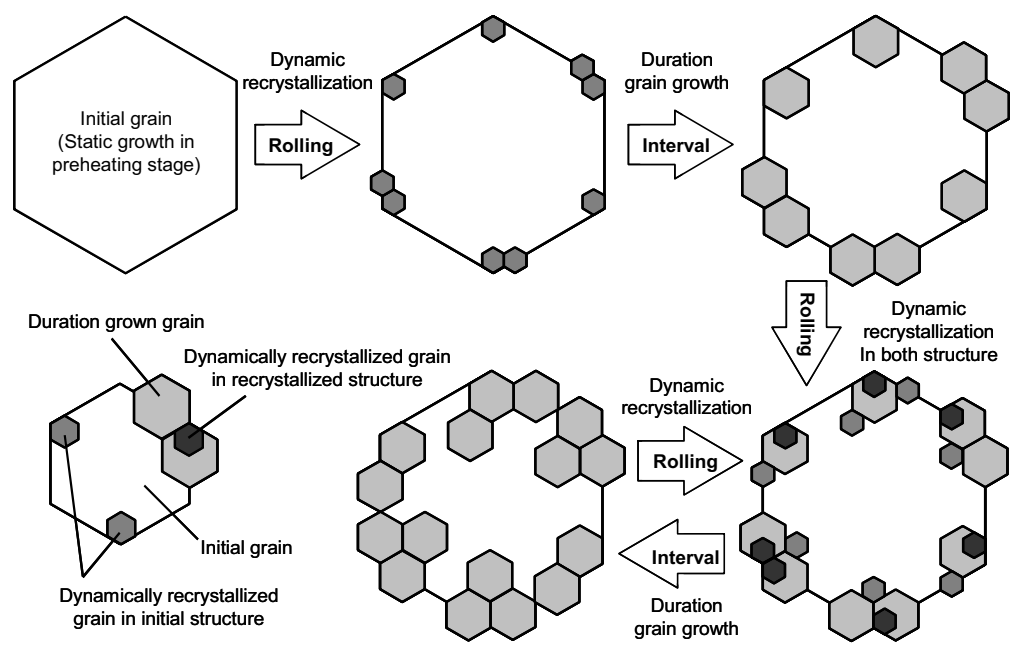

Figure 5. Proposed concept of microstructure evolution in calculation. 

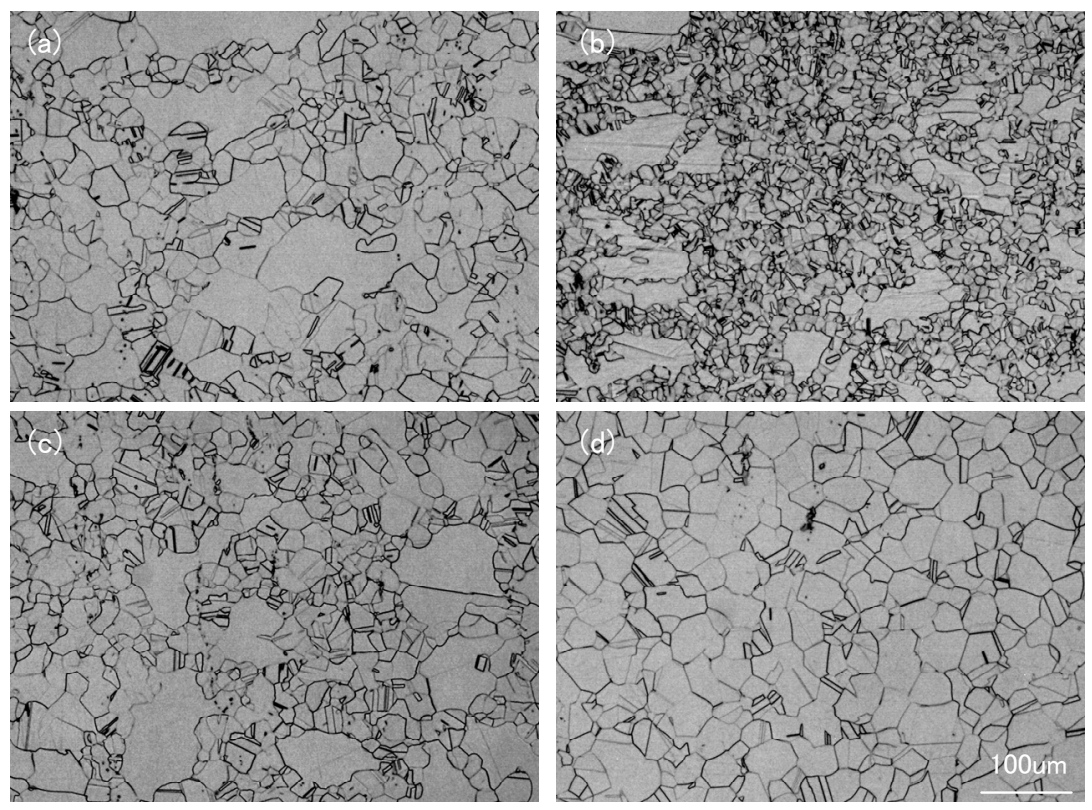

Figure 7. Typical microstructure after multi compression test (a) $1050^{\circ} \mathrm{C} /$ twice (b) $1050^{\circ} \mathrm{C} /$ four times (c) $1100^{\circ} \mathrm{C} /$ twice (d) $1100^{\circ} \mathrm{C} /$ four times.
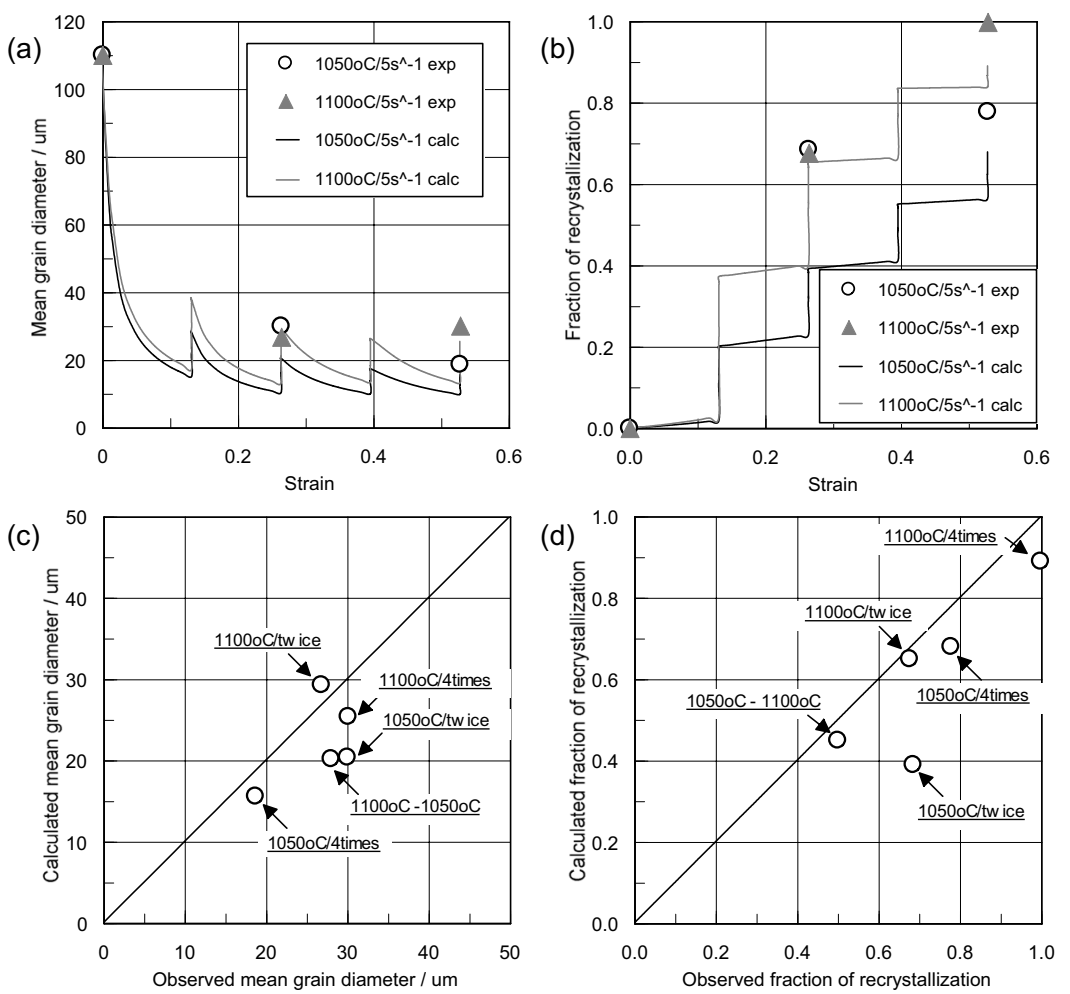

Figure 8. The comparison between prediction and observation in multi compression tests (a) transition of mean grain diameter as a function of total strain (b) transition of recrystallized fraction as a function of total strain (c) comparison of mean grain diameter (d) comparison of recrystallized fraction. 
temperature change.

Actual Casing Analysis

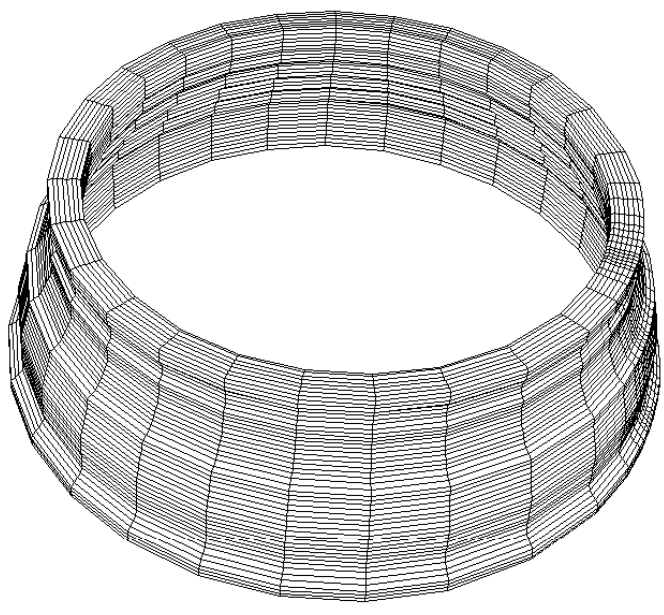

Accuracy of prediction system was evaluated for several kinds of actual casing with different size and shape. Figure 9 shows

Figure 9. Calculated final shape regarding to typical casing.

(a)

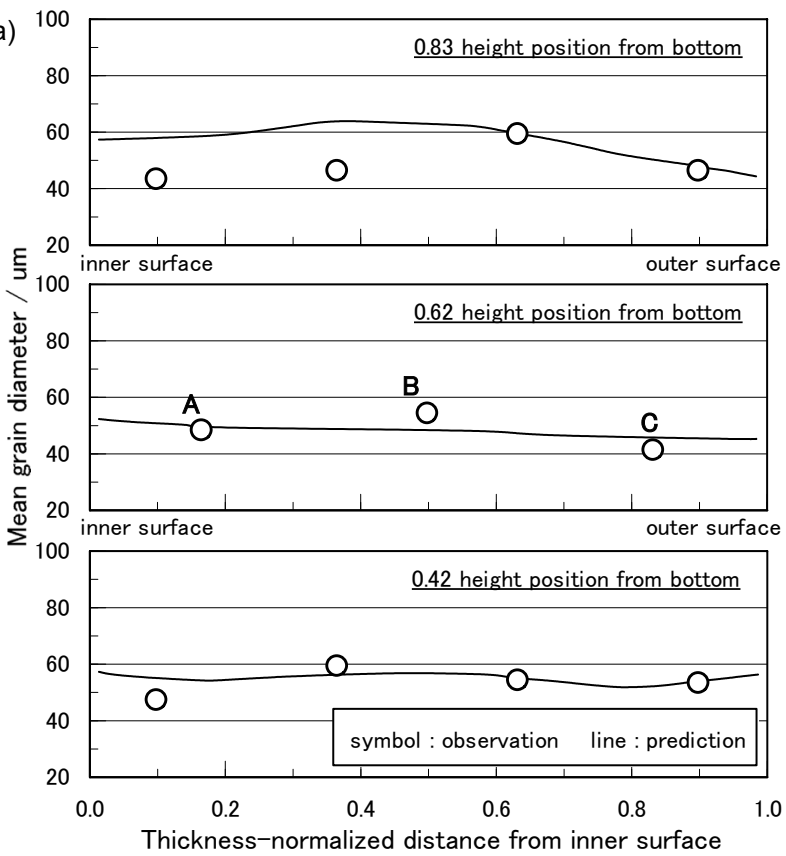

Figure 10. The mean grain diameter after solution and aging heat treatment and corresponding microstructure in actual casing (a) mean grain diameter distribution tendency in specific cross sections (b) representative microstructure.

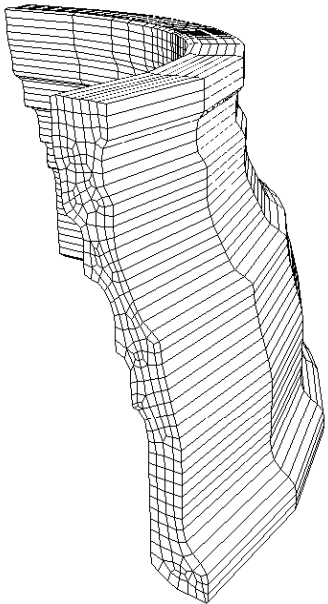

(b)
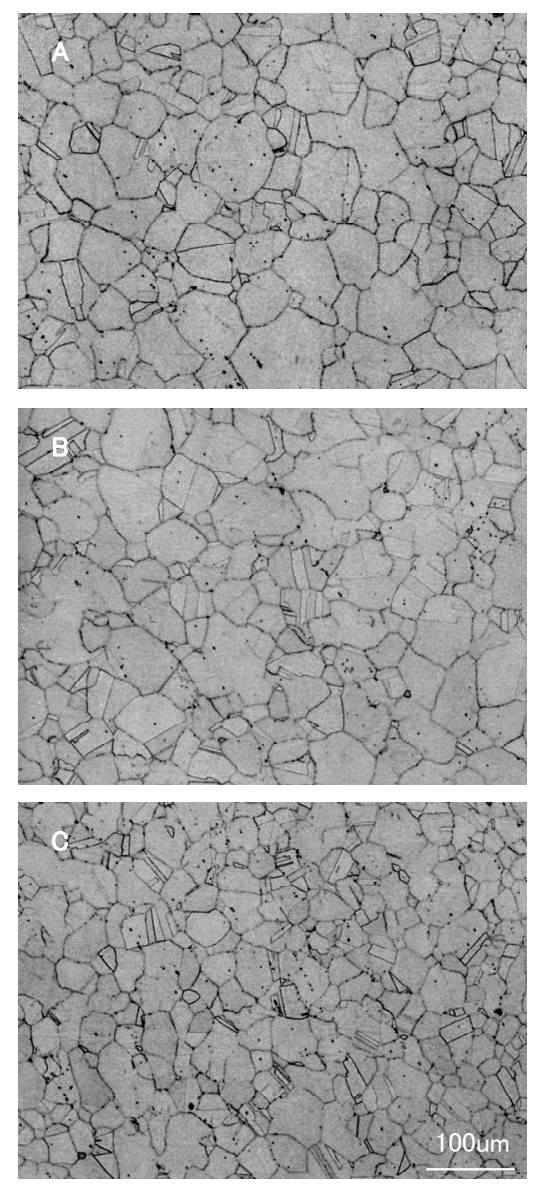
calculated final shape in case of typical casing with approximate $1 \mathrm{~m}$ in outer diameter. The prediction can follow the actual shape in spite of complicated near-net-shape. This agreement suggests suitableness of thermo-mechanical analysis technique in proposed prediction system. Waspaloy has large temperature and strain rate dependence on deformation behavior. These features that found in various gamma-gamma prime $\mathrm{Ni}$ base superalloys tend to induce the difficulty of deformation control in such extremely fitted nearnet-shape manufacturing. Therefore it is difficult to predict the deformation behavior and unsuitableness of prediction system must cause directly disagreement of final shape. The distribution of mean grain diameter after solution and aging heat treatment in three kinds of representative cross section and corresponding microstructure are shown in Figure 10. Chemical composition of that article is shown in Table II. It is confirmed that equiaxed and homogeneous grain structure, i.e. suitable one for casing, is obtained and the calculated distribution tendency along thickness direction agrees with observed one. Moreover a comparison of mean grain diameter between prediction and observation as to eighteen measurement points is summarized in Figure 11. The difference of average grain size between prediction and observation is less than ASTM No. $+1 /-1$ in any comparison point, although these points includes the region close to surface that will be removed in the following machining stage. Its accuracy is thought to be adequate for actual process design and several dozens of this article had produced using the prediction system and shipped until now. Furthermore similar precision was obtained in various parts and validity of proposed simulation system for Waspaloy was confirmed.

\section{Conclusions}

In this study, it was intended to develop ring rolling simulation system that has both adequate prediction accuracy and acceptable calculation time for industrial utilization. The following results were obtained.

The partial three-dimensional deformation model with novel velocity boundary conditions on imaginary cutting planes was proposed to obtain both practical prediction accuracy and

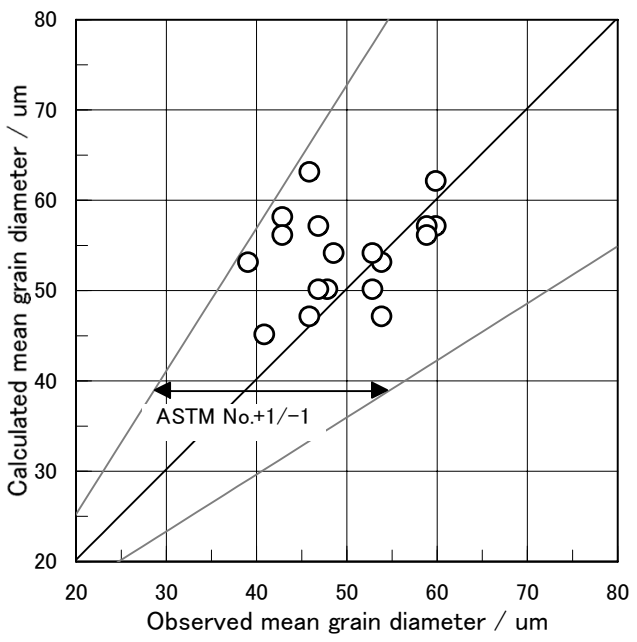

Figure 11. The comparison of mean grain diameter between prediction and observation in actual casing. acceptable computation time from industrial standpoint. Proposed partial three-dimensional model was confirmed to have equivalent accuracy to that of full three-dimensional model, while proposed model needed only extremely shorter calculation time than that of full three-dimensional model.

The relationship between microstructure and various parameters regarding to Waspaloy was evaluated and two kinds of microstructure prediction model were developed. One was static grain growth model that mainly corresponded to preheating process prior to ring rolling and the other was recrystallization model that represented ring rolling process itself. Moreover constructed microstructure prediction models were coupled to the finite element analyzing system to estimate mean grain diameter and fraction of recrystallization in addition to general output, such as temperature and strain.

The effectiveness of the proposed prediction system was confirmed through multi compression test and actual casing analysis. Several kinds of multi compression test with relatively high strain rate and small strain per bite were conducted not only under isothermal condition but also with temperature transition. Calculation could simulate characteristic transitions of mean grain diameter and fraction of recrystallization and sufficient agreement between calculation and observation was obtained. In actual article analysis, constructed prediction system could trace the shape in spite of extremely complicated near-net-shape. Moreover the difference of average grain size between prediction and observation was less than ASTM No. $+1 /-1$ in any comparison point. It showed that the proposed prediction system had adequate accuracy and enabled us to optimize the actual process design.

\section{References}

1. T.Matsui, H.Takizawa, H.Kikuchi and S.Wakita, "The Microstructure Prediction of Alloy720LI for Turbine Disk Applications", Superalloys 2000, (2000), 127-133.

2. G.Shen, J.Rollins and D.Furrer, "Microstructure Modeling of Forged Waspaloy Discs,” Superalloys 1996, (1996), 613-620.

3. A.J.Brand, K.Karhausen and R.Kopp, "Microstructural Simulation on Nickel Base Alloy Inconel718 in Production of Turbine Discs”, Mater. Sci. Tech., 12(1996), 963-969.

4. D.Huang et al., "Computer Simulation of Microstructure Evolution during Hot Forging of Waspaloy and Nickel Alloy718", Microstructure Modeling and Prediction During Thermomechanical Processing, (2001), 137-145.

5. S.Takahashi et al., "The Microstructure Prediction Model of Forged U720LI", Microstructure Modeling and Prediction During Thermomechanical Processing, (2001), 167-173.

6. M.J.Donachie et al., "Effect of Hot Work on the Properties of Waspaloy", Metall. Trans., 1(1970), 2623-2630.

7. A.A.Guimaraes and J.J.Jonas, "Recrystallization and Aging Effects Associated with the High Temperature Deformation of Waspaloy and Inconel718", Metall. Trans. A, 12A(1981), 16551666. 
8. N.Kim, S.Machida and S.Kobayashi, "Ring Rolling Process Simulation by the Three Dimensional Finite Element Method" Int. J. Mach. Tools Manufact., 30(1990), 569-577.

9. K,Traore et al, "Three Dimensional Finite Element Simulation of Ring Rolling", Simulation of Materials Processing, (2001), 595-600.

10. J.L.Song et al., "Coupled Thermo-mechanical Finite-element Modeling of Hot Ring Rolling Process", J. Mater. Process. Tech., 121(2002), 332-340.

11. T.C.Tszeng and T.Altan, "Investigation of Ring Rolling by Pseudo Plane-strain FEM Analysis", J. Mater. Process. Tech., 27(1991), 151-161.

12. K.Mori and N.Hiramatsu, "Simplified Three-dimensional FEM Simulation of Ring Rolling with Grooved Rolls", Simulation of Materials Processing, (2001), 607-612.

13. D.Y.Yang, K.H.Kim and J.B.Hawkyard, "Simulation of Tsection Profile Ring Rolling by the 3-D Rigid-plastic Finite Element Method”, Int. J. Mech. Sci, 33(1991), 541-550.

14. S.G.Xu et al., "Simulation of the Hot Ring Rolling Process by Using a Thermo-coupled Three-dimensional Rigid-viscoplastic Finite Element Method", J. Manufact. Sci. Eng., 119(1997), 542549

15. H.Takizawa, T.Matsui and H.Kikuchi, "Rigid-plastic Finite Element Analysis of Partially Modeled Ring Rolling", Simulation of Materials Processing, (2001), 601-606.

16. H.Takizawa, T.Matsui and H.Kikuchi, "Rigid-plastic Finite Element Analysis of Profile Ring Rolling by Partial 3D Model", Advanced Technology of Plasticity, (2002), 673-678. 
